\title{
Academic Integrity of Graduate Online Students in a Curriculum and Instruction Program
}

\author{
Charlotte Larkin ${ }^{1}$, Susan Szabo $^{2} \&$ Alma Mintu-Wimsatt ${ }^{3}$ \\ ${ }^{1}$ Department of Higher Education \& Learning Technologies, Texas A\&M University-Commerce, Commerce, TX, \\ USA \\ ${ }^{2}$ Department of Curriculum \& Instruction, Texas A\&M University-Commerce, Commerce, TX, USA \\ ${ }^{3}$ Department of Marketing \& Business Analytics, Texas A\&M University-Commerce, Commerce, TX, USA \\ Correspondence: Charlotte Larkin, Department of Higher Education \& Learning Technologies, Texas A\&M \\ University-Commerce, Commerce, TX 75428, USA. Tel: 903-886-5518.
}

Received: October 9, 2017

Accepted: October 30, 2017

Online Published: November 21, 2017

doi:10.5430/irhe.v2n4p1

URL: https://doi.org/10.5430/irhe.v2n4p1

\begin{abstract}
With the continued growth of online courses, the academic integrity of students has received much attention. While cheating is certainly not a new phenomenon, the role of technology in the learning environment has mitigated the effectiveness of traditional preventative measures to maintain academic integrity. This research seeks to examine perceptions of cheating among online graduate students enrolled in a Curriculum and Instruction (C\&I) program. We found that in general, students believe that cheating is more prevalent and more likely to occur in an online learning platform. Moreover, despite students' awareness of university policies and consequences, this has not deterred some from cheating. However, it appears that faculty engagement in setting parameters for what constitutes cheating is important.
\end{abstract}

Keywords: online learning, cheating, academic integrity

\section{Introduction}

The number of students participating in college-level online courses has outpaced all other forms of distance learning (Raines, Ricci, Brown, Eggenberger, Hindle, \& Schiff, 2011). Online learning is a valuable commodity to higher education where institutions can extend their academic missions beyond their traditional brick-and-mortar campuses. Although online learning has become a definite asset to institutions and learners alike, the problem of academic integrity has emerged as an important issue for this new educational delivery platform (Etter, Cramer, \& Finn, 2006; Grijalva, Nowell, \& Kerkvliet, 2006; Kennedy, Nowak, Raghuraman, Thomas, \& Davis,, 2000; Lanier, 2006; Underwood \& Szabo, 2003). In fact, academic dishonesty has become so widespread that the print media has called the problem a "plague" (Embleton \& Helfer, 2007) and scholars have labeled it a "crisis on campus" (Burke, PoUmeui, $\&$ Slavin, 2007). And most alarming, some have asserted that there exists a 'cheating culture' whereby students have become nonchalant and/or tolerant of cheating (Larkin \& Mintu-Wimsatt, 2015). In fact, rationalization/attitude becomes prevalent and excusable when there is a perception that "everyone is doing it" (King, Guyette, \& Piotrowski, 2009). On the other hand, several researchers have downplayed concerns about online academic integrity issues. Grijalva, et al. (2006) showed that academic dishonesty in online classes is no more pervasive than in traditional classes.

\subsection{Importance of the Problem}

While there have been a plethora of studies conducted on cheating in face-to-face classes, studies conducted on online courses have been sporadic (e.g., Grijalva et al., 2006; Lanier, 2006; Stuber-McEwen, Wiseley, \& Hoggatt, 2009; Szabo \& Underwood, 2003, 2004, Swartz \& Cole, 2013). This gap in the literature is unfortunate given that the popularity of Web-based courses demands that researchers study academic integrity in ways that they have not before while utilizing previous research to guide them in how to best predict and eliminate cheating. Gaining insights into academic integrity in this new learning environment can ensure that retain their [academic] moral compass and become honest employees and/or community members (Larkin \& Mintu-Wimsatt, 2015). To help address the aforementioned gap in the literature, our research seeks to examine academic integrity among online graduate students in a $\mathrm{C} \& \mathrm{I}$ program by examining their perceptions of cheating. 


\subsection{Background Literature}

The exponential growth in online learning opportunities has brought to the forefront the concern for academic integrity (Raines et al., 2011). Indeed, academic integrity has become a major concern for instructors involved in the implementation and teaching of online courses (Trenholm, 2006-2007). Academic dishonesty comprises multiple behaviors and varies in severity. It includes unauthorized collaborating on homework, using "cheat sheets" during an exam, and plagiarizing assignments. In more extreme forms, academic dishonesty involves students purchasing term papers from paper mills.

The premise of academic integrity lies in intellectual honesty. It encompasses honesty, trust, fairness, respect, and responsibility (Swartz \& Cole, 2013). Academic integrity has been defined by East and Donnelly (2012) as 'understanding what it means to be honest in the particular culture of the academic world, and being able to apply the scholarly conventions of acknowledgment' (in Larkin \& Mintu-Wimsatt, 2015, p. 56). Cheating is defined by King et al. (2009) "as a transgression against academic integrity which entails taking unfair advantage that results in a misrepresentation of a student's ability and grasp of knowledge" (p. 4). Consequently, 'academic integrity' is often used interchangeably with 'cheating.'

\subsection{Students' Online Cheating}

Previous research has found that students perceived cheating to be easier in online course (Guyette et al., 2008). Many instructors have acknowledged that dishonesty in online classes is easier because of readily available materials via the Internet (Renard, 2000). In addition, Swartz and Cole (2013) reported that students found cheating online to be easier because the student is off-site and unsupervised. Peer standards of behavior, and even ignorance to the fact that their behaviors are in violation of the university's student code of ethics, are reasons often cited for cheating (McCabe, Butterfield, \& Trevino, 2012).

Travis and Price (2005) stated that faculty using distance education technology are often faced with academic integrity issues particularly with written examinations. Because of the Internet, students can readily find written work electronically and manipulate it to make it their own. Travis and Price (2005) indicated that any written work required in web-based classes could be viewed as an enticement for students to be dishonest, causing faculty to consider the implementation of safeguards, many of which may not be completely effective.

A study conducted by Brown (1996) found that $85.7 \%$ of education online students reported participating in at least one unethical practice. This statistic is higher when compared to business $(81.2 \%)$ and engineering $(80.2 \%)$ students. Education students were more likely than engineering students to do so "to get a high grade" and were more likely than engineering or business students to behave dishonestly because of peer pressure. Results also showed that students generally wanted good grades but did not want to study for them, and they felt that no one suffered from their cheating. Laziness, lack of preparation time for assignments and exams, lack of interest in the subject matter, and even rebellion are other commonly cited reasons for cheating (Ashworty \& Bannister, 1997). Some also stated that although they knew that cheating was morally wrong, students justified that their behaviors were driven by competition. That is, the "desire to get ahead" is the most common explanation for cheating (Simkin \& McLeod, 2010).

Nath and Lovaglia (2009) found two thirds of cheating cases among online students involved getting together during an exam and the other one third involved copying another student's paper without his/her knowledge. In addition, students often have private email conversations with peers when taking online examinations. Obviously, instructors have no knowledge of these conversations. In some cases, students accessed and downloaded class assessments prior to examination dates, looked up answers, and shared them with classmates via email (Olt, 2002).

\subsection{Faculty Perceptions of Online Cheating}

According to Malesky, Baley and Crow (2016), faculty are often uncertain about the extent of cheating at their college. But, most take corrective action once they discover an instance of cheating has been reported (Larkin \& Mintu-Wimsatt, 2015). However, faculty reactions to cheating may not necessarily be in line with the university's institutional policy although they are aware of the required steps. Different safeguards are used to protect the integrity of their courses, but there is an apparent lack of knowledge about available safeguards and their use (Malesky, Baley \& Crow, 2016).

\subsection{Purpose of This Study}

To further investigate academic integrity, we conducted a study on the cheating perceptions and behaviors of students. This study specifically examined cheating among graduate online Curriculum and Instruction (hereafter C\&I) students. The following research questions were explored: 
RQ1: Is cheating easier in an online learning environment?

RQ2: What are students' perceptions with regards to plagiarism in an online learning environment?

RQ3: What are the students' impressions of the University's policy and instructor's engagement regarding cheating?

\section{Method}

\subsection{Survey}

The survey questions utilized in this study was adopted from Larkin and Mintu-Wimsatt (2015). These authors conducted a similar study on online cheating among undergraduate and graduate business students.

\subsection{Sample Size}

This study utilized the responses of graduate students enrolled in an online C\&I program. These students attend a mid-sized regional state university in east Texas. An email was initially sent to 50 students seeking their voluntary participation in an anonymous online survey. Of the 50 students, 30 completed the survey.

\subsection{Sample Selection}

Given the sensitive nature of the survey, this research was conducted on a voluntary basis. As a result, the effective sample size is relatively small. The researchers deemed it unethical to provide students with extra credit points for survey participation [to boost sample size] since this would necessitate having to determine the names of the respondents.

Students were initially contacted through a petition from a university faculty member teaching the C\&I course. Students were given a secure web address to visit and complete the survey. The survey was intended to gauge the level and type of academic dishonesty among online graduate C\&I students. Of the 30 participants, 29 identified themselves as female and one as male. Additionally, 15 students identified themselves as master's students, 13 as doctoral students and 2 as other.

\section{Results}

The focus of this study was to further look into academic dishonesty perceptions and behaviors of graduate students in an online C\&I program based on the research questions provided earlier. Presented below are the key findings in this study.

\subsection{Students' Perceptions of \& Reactions to Online Cheating}

Based on the results reported in this study, we found that: (1) The majority (53\%) of students collectively believe that cheating takes place 'often' and 'sometimes' during testing; and, (2) Sixty five percent (65\%) believe that cheating is easy to do online. Approximately fifty nine percent (59\%) are likely to report online cheating infractions. The rest of the sample either won't report the incident (24\%) or opted to not respond to the question (17\%).

Table 1. Students' self-reported perceptions of online cheating

\begin{tabular}{lc}
\hline & Response \\
\hline How frequently do you think cheating during a test occurs? & \\
\hline Rarely & $46.67 \%$ \\
\hline Sometimes & $46.67 \%$ \\
\hline Often & $6.67 \%$ \\
\hline & \\
\hline I believe that students cheat because it is easy to cheat & $64.52 \%$ \\
\hline Yes & $35.48 \%$ \\
\hline No & $0.00 \%$ \\
\hline I prefer not to answer &
\end{tabular}

How likely are you to report an incident of cheating that you observed? 


\begin{tabular}{ll}
\hline Very unlikely & $24.14 \%$ \\
\hline Very likely & $58.62 \%$ \\
\hline I prefer not to answer & $17.24 \%$ \\
\hline
\end{tabular}

\subsection{What Students Think of Plagiarism}

Based on the tabulated responses in Table 2, it appears that students generally have a clear idea of what is not acceptable in an online learning environment particularly as it relates to plagiarism. In general, students were very much aware that using or copying others' work without proper citation as well as copying materials from the Internet/Web are all considered as plagiarism. Unfortunately, $73 \%$ of these students collectively believed that plagiarism occurs 'often' and 'sometimes.' Thirty percent (30\%) said that copying/using materials from the Internet is 'always okay' while twenty percent (29\%) suggested that incorrect referencing is acceptable.

Table 2. Students' self-reported perceptions of plagiarism

\section{Response}

Plagiarism is using the ideas and words of someone else as my own work without citing the original work.

\begin{tabular}{lc}
\hline Yes & $96.67 \%$ \\
\hline No & $3.33 \%$ \\
\hline I prefer not to answer & $0.0 \%$ \\
\hline
\end{tabular}

\begin{tabular}{lc}
\hline How frequently do you think plagiarism on a written assignment occurs? & \\
\hline Rarely & $26.67 \%$ \\
\hline Sometimes & $66.676 \%$ \\
\hline Often & $6.67 \%$ \\
\hline
\end{tabular}

\begin{tabular}{lc}
\hline Copying anything from the Internet/Web and using it as my own work is considered plagiarism. \\
\hline Yes & $93.33 \%$ \\
\hline No & $6.67 \%$ \\
\hline I prefer not to answer & $0.0 \%$ \\
\hline
\end{tabular}

\begin{tabular}{lc}
\hline Using something I find on the Internet/Web for a class assignment is always okay. \\
\hline Yes & $30.00 \%$ \\
\hline No & $70.00 \%$ \\
\hline I prefer not to answer & $0.0 \%$ \\
\hline
\end{tabular}

\subsection{Policy and Instructor Awareness}

The data in Table 3 shows that online students were generally aware of the university's policy on cheating/plagiarism as well as the potential penalties. This high level of awareness may be driven by the instructor's engagement in terms of explaining and/or discussing matters regarding the parameters for academic dishonesty. 
Table 3. Students self-reported perceptions on university policy \& instructor awareness

\begin{tabular}{|c|c|}
\hline & Response \\
\hline \multicolumn{2}{|c|}{ I am familiar with my school's policy on cheating and/or plagiarism } \\
\hline Yes & $93.33 \%$ \\
\hline No & $6.67 \%$ \\
\hline I prefer not to answer & $0.0 \%$ \\
\hline \multicolumn{2}{|c|}{ The severity of penalties for cheating is } \\
\hline Very low & $0.00 \%$ \\
\hline Medium & $26.67 \%$ \\
\hline Very high & $73.33 \%$ \\
\hline \multicolumn{2}{|c|}{$\begin{array}{l}\text { The average student's understanding of University policies concerning } \\
\text { cheating is }\end{array}$} \\
\hline Very low & $26.67 \%$ \\
\hline Medium & $46.67 \%$ \\
\hline Very high & $46.67 \%$ \\
\hline \multicolumn{2}{|c|}{ How often does your instructor discuss policies concerning plagiarism? } \\
\hline Rarely & $36.67 \%$ \\
\hline About half the time & $26.67 \%$ \\
\hline Most of the time & $36.67 \%$ \\
\hline
\end{tabular}

How often does your instructor discuss policies concerning proper citation/referencing of written sources?

\begin{tabular}{ll}
\hline Rarely & $23.33 \%$ \\
\hline About half the time & $26.67 \%$ \\
\hline Most of the time & $50.00 \%$ \\
\hline
\end{tabular}

How often does your instructor discuss policies concerning proper citation/referencing of Internet sources?

\begin{tabular}{ll}
\hline Rarely & $26.67 \%$ \\
\hline About half the time & $26.67 \%$ \\
\hline Most of the time & $46.67 \%$ \\
\hline
\end{tabular}

My university has information on the Internet/Web that can help me understand how to avoid plagiarism.

\begin{tabular}{lc}
\hline Yes & $93.33 \%$ \\
\hline No & $0.00 \%$ \\
\hline I prefer not to answer & $6.67 \%$ \\
\hline
\end{tabular}




\begin{tabular}{lc}
\hline $\begin{array}{l}\text { There are Internet/Web sites that my instructor can use to search for } \\
\text { sources of the information I used in a class assignment. }\end{array}$ \\
\hline Yes & $100.00 \%$ \\
\hline No & $0.00 \%$ \\
\hline
\end{tabular}

If I am found guilty of Academic Dishonesty, it could be placed on my permanent transcript.

\begin{tabular}{ll}
\hline Yes & $86.67 \%$ \\
\hline No & $6.67 \%$ \\
\hline I prefer not to answer & $6.67 \%$ \\
\hline
\end{tabular}

\section{Discussion}

The results in this study are consistent with previous works (i.e., Larkin \& Mintu-Wimsatt, 2015; Guyette et al., 2008) that suggested students themselves are inclined to believe that cheating is easier online. In fact, there is a perception that cheating is not only easier but also fairly common. This is unfortunate despite the emphasis placed by the university on the importance of the ethical code of conduct as well the sample's self-reported awareness/familiarity with university policies and penalties.

Our findings also noted that while students were aware that plagiarism is a form of cheating, some of their ideas on what comprises plagiarism are erroneous. Our data suggested that some students believed information found on the Internet is 'fair game' and incorrect citation is acceptable. This is consistent with previous research (i.e., Lorenzetti, 2010) that has shown that many students do not identify "cutting and pasting" as plagiarism. Therefore, it is imperative that instructors explicitly address what constitutes unacceptable plagiarism-related behaviors.

The students sampled in this study were also very much aware of the university's policies regarding cheating as well as the consequences. Their responses suggested that their instructor had provided them with significant information pertaining to online cheating. This is consistent with Howell et al.'s (2010) admonition that distance educators need to protect the integrity of their courses/programs and prevent cheating whenever possible. Educators have to spend the necessary time or resources to prevent and/or detect cheating. Confronting cheaters and spending resources on deterrents, detection, and discipline is critical in mitigating academic online cheating.

Lorenzetti (2010) identified three ways universities can address academic dishonesty: (1) Policing or intensifying efforts to identify academic dishonesty and punish those who engage in this behavior; (2) Prevention or enhancing efforts to create barriers, such as prevention tools (e.g., provide proctoring mechanism) and test design (e.g., timed completion of the assessment and limited numbers of log-ins during the exam); and (3) Ethical engagement, this is the "most difficult approach," as it strives to ethically and academically encourage students to want to do their own work. The key is to develop students who do not want to cheat.

\section{Conclusions, Limitations and Future Research}

As online courses continue to spread through higher education, more research will be needed to provide insights on academic dishonesty. Unfortunately, researchers have to rely on students' self-reported responses regarding this sensitive topic. As a result, it is not surprising that studies such as ours had a low response rate. As reported earlier, of the 50 graduate C\&I students surveyed, only 30 chose to participate. Given the sensitive nature of 'cheating,' the level of students' honesty is hard to ascertain. Despite the anonymous nature of the survey conducted as well as the instructor's assurances of non-identification of respondents, it is inevitable that some were hesitant to provide truthful answers.

This study was conducted among graduate C\&I students. It would be interesting to conduct a future study to examine the prevalence of cheating among undergraduate students in C\&I. Furthermore, online students, both graduate and undergraduate, from other disciplines should be included in future studies. Other possible topics include exploring the different tools students use to cheat as well as how cheating occurs. That is, have smart phones enabled students to cheat more readily. Or, are students more likely to cheat when writing a research paper or during testing? 


\section{References}

Ashworty, P., \& Bannister, P. (1997). Guilty in whose eyes? University students' perceptions of cheating and plagiarism in academic work and assessment. Studies in Higher Education, 22(2), 187-196. https://doi.org/10.1080/03075079712331381034

Brown, B. (1996). A comparison of the academic ethics of graduate business, education, and engineering students. College Student Journal, 30, 294-301.

Burke, J., PoUmeui, R., \& Slavin, N. (2007). Academic dishonesty: A crisis on campus. CPA Journal, 77(5), 58-65.

East, J., \& Donnelly, L. (2012). Taking responsibility for academic integrity: A collaborative teaching and learning design. Journal of University Teaching and Learning Practices, 9(3).

Embleton, K., \& Helfer, D. (2007). The plague of plagiarism and academic dishonesty. Searcher, 15(6).

Etter, S., Cramer, J., \& Finn, S. (2006). Origins of academic dishonesty: Ethical orientations and personality factors associated with attitudes about cheating with information technology. Journal of Research on Technology in Education, 39, 133-155. https://doi.org/10.1080/15391523.2006.10782477

Guyette, Jr. R., King, C., \& Piotrowski, C., (2008). Business faculty views of online course cheating: Evidence for a cohort effect. Organization Development Journal, 26(4).

Grijalva, T., Nowell, C., \& Kerkvliet, J. (2006). Academic honesty and online courses. College Student Journal, 40(1), 180-185.

Howell, S., Sorensen, D., \& Tippets, H. (2010). The new news about cheating for distance educators. Promoting Academic Integrity in Online Education. Retrieved from http://www.facultyfocus.com/

Kennedy, K., Nowak, S., Raghuraman, R., Thomas, J., \& Davis, S. (2000). Academic dishonesty and distance learning: Student and faculty views. College Student Journal, 34(2).

Kennedy, P., Bisping, O., Patron, H., \& Roskelley, K. (2008). Modeling academic dishonesty: The role of student perceptions and misconduct type. Journal of Economic Education 39(1), 4-21. https://doi.org/10.3200/JECE.39.1.4-21

King, C., Guyette, R., \& Piotrowski, C., (2009). Online exams and cheating: An empirical analysis of business students' views. Journal of Educators Online, 6(1). https://doi.org/10.9743/JEO.2009.1.5

Lanier, M. (2006). Academic integrity and distance learning. Journal of Criminal Justice Education, 17(2), 244-261. https://doi.org/10.1080/10511250600866166

Larkin, C., \& Mintu-Wimsatt, A. (2015). Comparing cheating behaviors among graduate and undergraduate online business students. Journal of Higher Education Theory and Practice, 15(7), 54-62.

Lorenzetti, J. (2010). Combating online dishonesty with communities of integrity. Promoting Academic Integrity in Online Education. Retrieved from http://www.facultyfocus.com/

Malesky Jr. L.A., Baley, J., \& Crow, R. (2016). Academic dishonesty: Assessing the threat of cheating companies to online education, College Teaching, 64(4), 178-183. https://doi.org/10.1080/87567555.2015.1133558

McCabe, D., L., Butterfield, K. D., \& Trevino, L. K. (2012). Cheating in college: Why students do it and what educators can do about it. Baltimore, MD: Johns Hopkins University Press.

Nath, L., \& Lovaglia, M. (2009). Cheating on multiple-choice exams: Monitoring, assessment, and an optional assignment [Electronic version]. College Teaching, 57, 3-8. https://doi.org/10.3200/CTCH.57.1.3-8

Olt, M. (2002). Ethics and distance education: Strategies for minimizing academic dishonesty in online assessment. Online Journal of Distance Learning Administration, 5(3), 1-7.

Raines, D., Ricci, P., Brown, S., Eggenberger, T., Hindle, T., \& Schiff, M. (2011). Cheating in online courses: The student definition. The Journal of Effective Teaching, 11(1), 80-89.

Renard, L. (2000). Cut and paste 101: Plagiarism and the net. Educational Leadership, 5(4), 38-42,

Sileo, J., \& Sileo. T. (2008). Academic dishonesty and online classes: A rural education perspective. Rural Special Education Quarterly, 27(1/2), 55-60. https://doi.org/10.1177/8756870508027001-209

Stuber-McEwen, D., Wiseley, P., \& Hoggatt, S. (2009). Point, click, and cheat: Frequency and type of academic dishonesty in the virtual classroom. Online Journal of Distance Learning Administration, 12(3), 1-10. 
Swartz, L., \& Cole, M. (2013). Students' perceptions of academic integrity in online business education courses. Journal of Business \& Educational Leadership, 4(1), 102-11.

Szabo, A., \& Underwood, J. (2003). Academic offences and e-learning: individual propensities in cheating. British Journal of Educational Technology, 34(4), 467-477. https://doi.org/10.1111/1467-8535.00343

Szabo, A., \& Underwood, J. (2004). Cybercheats: Is information and communication technology fueling academic dishonesty?. Active Learning in Higher Education, 5(2), 180-199. https://doi.org/10.1177/1469787404043815

Tilsley, A. (2012). Paying for an A. Retrieved from https://www.insidehighered.com/news/2012/09/21/sites-offering-take-courses-fee-pose-risk-online-ed

Travis, J., \& Price, K. (2005). Instructional culture and distance learning [Electronic version]. Journal of Faculty Development, 20, 99-103.

Trenholm, S. (2006-2007). A review of cheating in fully asynchronous online courses: A math or fact-based course perspective [Electronic version]. Journal of Educational Technology Systems, 35, 281-300. https://doi.org/10.2190/Y78L-H21X-241N-7Q02

Young, J. (2010). High-tech cheating abounds, and professors bear some blame [Electronic version]. Chronicle of Higher Education, 56, 1-14.

Young, J. (2013). Online classes see cheating go high-tech. Education Digest, 78(5), 4-8. 